\title{
An integrated quantitative approach to assess the archaeological heritage in highly anthropized areas: the case study of Aesernia (southern Italy)
}

\author{
Vincenzo Amato ${ }^{1}$, Marilena Cozzolino ${ }^{2}$, Gianfranco De Benedittis ${ }^{2}$, Gianluigi Di Paola ${ }^{1}$, Vincenzo \\ Gentile $^{2}$, Claudia Giordano ${ }^{1}$, Pasquale Marino ${ }^{3}$, Carmen Maria Rosskopf ${ }^{1}$, Ettore Valente ${ }^{2}$ \\ ${ }^{1}$ University of Molise, Department of Biosciences and Territory, Contrada Fonte Lappone, Pesche (IS), Italy \\ ${ }^{2}$ University of Molise, Department of Social, Human and Educational Science, Via De Sanctis, Campobasso, Italy \\ ${ }^{3}$ Second University of Naples, Department of Architetture and Industrial Design, Via San Lorenzo, Aversa (CE), Italy
}

\begin{abstract}
The Latin colony of Aesernia was the seat of an important road junction for communications, especially to the south with Bovianum and Beneventum, to the north with Aufidena and the Sangro Valley and to the west with Venafrum and the Liri River Valley.

While some archaeological contexts of this colony are documented by very detailed studies, others still require an overall analysis and a systematic study. Particularly, there is the lack of an organic and complete reading of the known data and a concrete need to acquire new data on still unexplored areas.

The present paper illustrates the results of the integrated geo-archaeological research carried out at Isernia and based on the analysis of historical sources, archaeological surveys, geologic, geomorphological and topographic investigations and geophysical prospections. All data were stored in a Geographic Information System that allowed for spatial analyses and the production of thematic maps. The purpose of the research was to help fill the many knowledge gaps in the history of Aesernia and to add new data by using a multiple system of analysis. The integrated geo-archaeological approach allowed drawing up a new archaeological map that gives an updated view of the rich archaeological heritage of Isernia.
\end{abstract}

\section{Section: RESEARCH PAPER}

Keywords: Latin Colony of Aesernia; archaeological survey; geophysical prospection; geological-geomorphological and GIS analyses; thematic maps

Citation: Vincenzo Amato, Marilena Cozzolino, Gianfranco De Benedittis, Gianluigi Di Paola, Vincenzo Gentile, Claudia Giordano, Pasquale Marino, Carmen Maria Rosskopf, Ettore Valente, An integrated quantitative approach to assess the archaeological heritage in highly anthropized areas: the case study of Aesernia (southern Italy), Acta IMEKO, vol. 5, no. 2, article 6, September 2016, identifier: IMEKO-ACTA-05 (2016)-02-06

Section Editors: Sabrina Grassini, Politecnico di Torino, Italy; Alfonso Santoriello, Università di Salerno, Italy

Received March 22, 2016; In final form July 18, 2016; Published September 2016

Copyright: (C) 2016 IMEKO. This is an open-access article distributed under the terms of the Creative Commons Attribution 3.0 License, which permits unrestricted use, distribution, and reproduction in any medium, provided the original author and source are credited

Corresponding author: Marilena Cozzolino, e-mail: marilena.cozzolino@unimol.it

\section{INTRODUCTION}

The city of Isernia is located in the Molise Region (southern Italy) at about $420 \mathrm{~m}$ a.s.l. on a fluvial terrace limited by the incisions of the Carpino and the Sordo rivers (Figure 1). The area of Isernia was settled at least during the Lower Palaeolithic Era as evidenced by the renowned site of Isernia La Pineta [1], [2]. The actual setting of the historical centre of Isernia still reflects the ancient distribution of the Roman colony which was founded in 263 BC (Liv., XVI, 48).

Walls built up with the technique opus polygonal surrounded the city and the urban plan was characterized by a complex distribution of artificial terraces connected by a principal axis (the actual Corso Marcelli, Figure 1) that crossed the entire residential area. These walls, mainly made of large travertine blocks quarried in local travertine outcrops, were found along the borders of the elongated ridge lying on the travertine substratum.

Over the centuries, many natural events, especially earthquakes, along with human processes and historical events have led to profound modifications of the urban fabric. Nowadays, the widespread presence of buildings and paved areas in the historical centre represents a big, sometimes 


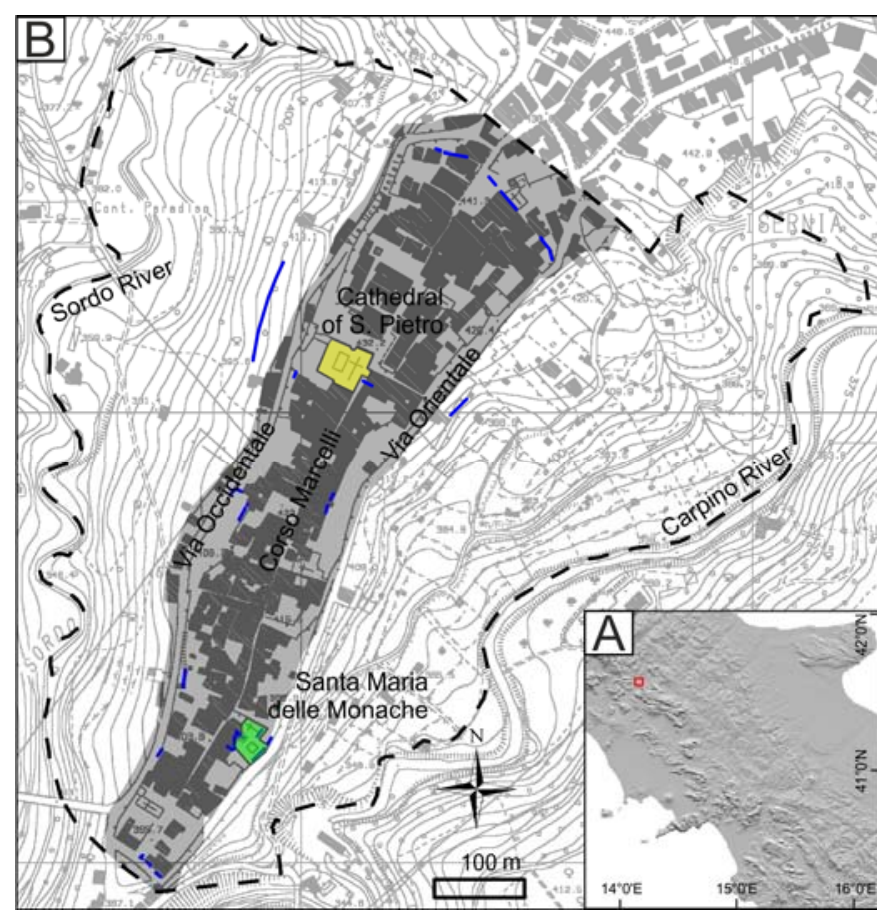

Figure 1. A) Location of Isernia (Molise Region, Italy): B) Excerpt of the topographic map at scale 1:5,000 including the historical centre of Isernia. Its urban area is shown in grey. The dotted black line limits the peri-urban area. The blue lines indicate already known archaeological evidences.

insurmountable obstacle for the observation and the interpretation of the complex and multi-layered archaeological data. Numerous archaeological excavations and explorations have been carried out in recent years in the territory of Isernia by the Superintendency for the Archaeological Heritage of the Molise Region.

In 1977, a speleological group of the city of L'Aquila explored and revealed the entire aqueduct of the Roman city, identifying its path and various accesses [3]. In the Isernia historical centre the aqueduct path follows the actual Corso Marcelli.

In 1980, archaeological excavations in the underground of the S. Pietro Cathedral (Figure 1) brought to light the podium of the temple of the colony dating to the third century BC [4].

Subsequently, in 1982, excavations within the Lombard monastery of Santa Maria delle Monache (Figure 1) dated to the end of the VI century AC have enabled the discovering of two fragments of the walls built with the technique of polygonal opus and of some rooms of the Roman imperial age [5].

In the following year, a necropolis consisting of about 110 tombs, ranging in age between the I and the IV century AC [6], [7], was found in the locality of Quadrella, just outside the western walls.

In 1984, during the works for the building of the new hospital complex, located in the southwestern part of the modern city, just outside the SW door of the ancient colony, a thermal bath system of imperial Roman times was discovered [8].

In the late 1980s, during the restoration of the courtyard of the bishop's palace, a podium of a second temple dating to the second half of the I century BC was brought to light [9] in the west side of the temple of the colony.

In the 1990s, thanks to the realization of public works, such as the parking lots in Via Occidentale and Via Orientale (Figure
1), a stretch of a Late Ancient wall and a gutter in stone blocks [10] along with fragments of walls referable to buildings of the Roman period [11] were discovered.

Finally, in the early 2000s, a very important contribution to the global analysis of the cultural heritage of the territory of Isernia was offered by the publication of a book [12] that collects all known archaeological evidence until that date.

While some archaeological contexts of the historical centre of Isernia can now rely on a rich literature and updated results, other areas still require a detailed overall analysis and, especially, a systematic study. Many archaeological materials derived from emergency excavations during either public or private works are actually unstudied. Generally, there is the lack of an organic and complete "reading" of the known data and a concrete need to acquire new information on areas which have never been investigated to date. Particularly, an extensive archaeological survey and study has never been carried out in the areas immediately outside the wall.

To standardize and store the myriad of archaeological data from Isernia and to add new data on areas yet unexplored, in this work an integrated quantitative multidisciplinary approach has been adopted complying the following workflow:

Census of all known archaeological findings of Isernia through bibliographic analysis.

Implementation, for the first time, of a detailed and updated archaeological database.

Entering of this database in a geographical information system by using the software ArcMap 10.1 in order to apply spatial analysis techniques and to derive thematic maps.

Archaeological field survey for the detection of new archaeological findings in the numerous unexplored areas. Creation of high resolution DEMs for the historical centre (urban area) of Isernia $(0.5 \mathrm{~m})$ and the peri-urban area $(5$ $\mathrm{m})$ by means of a GIS analysis of large scale topographic maps (CTR at scale 1:5,000, Molise Region) and photogrammetric survey data (scale 1:500) along with GPS measurements in some crucial urban areas.

Integrated analysis of geologic-stratigraphic and geomorphological data mainly provided by field surveys, boreholes, topographic maps and DEMs.

Drawing up of a detailed geological map (scale 1:5,000) and geological cross sections of the area of Isernia in order to contextualize both the emerged and buried archaeological findings and to identify layers in the subsurface with a high archaeological potential.

Implementation of non-invasive systematic geophysical prospecting in order to better define the archaeological findings identified in some areas during the previous archaeological fieldwork and detect new archaeological findings in urban sectors with high archaeological potential in which direct interventions have not been possible to date.

Generation of an updated computerized map of the archaeological evidences of the study area as a product useful for the promotion of the archaeological heritage.

\section{TOPOGRAPHIC ANALYSIS}

\subsection{Methods}

A large-scale analysis of topographic features was performed. This analysis was carried out on CTR (Carta 
Tecnica Regionale, Molise Region) topographic maps at scale 1:5,000 investigated in a GIS environment by using the software ArcGIS 10.1. Moreover, $5 \mathrm{~m}$ spaced contour lines and elevations on the topographic maps, once digitalized, were interpolated with the Topo to Raster tool in order to derive a 5 $\mathrm{m}$ DTM for the study area. This $5 \mathrm{~m}$ DTM clearly distinguishes the gentle SW dipping surface that hosts the historical centre of Isernia (urban area) from the adjacent steeper slopes that host the peri-urban area and extend up to the thalwegs of the Sordo and Carpino rivers. Unfortunately, this DTM shows no topographic detail of the urban area due to its almost flat topography. To overwhelm this problem, we derived a more detailed DTM for this area by re-elaborating a very detailed aerial photogrammetric survey dating to the late 1980s that allowed for the reconstruction of $0.5 \mathrm{~m}$ spaced contour lines and elevations with centimeter accuracy. A first interpolation of these data allowed a very good topographic reconstruction of the valley slopes due to the high number of mapped contour lines but only a poorly constrained reconstruction of the urban area. In this area, in fact, the GIS interpolation created several peaks that have no correspondence with the actual topography. This incongruence is due to the non-homogeneous distribution of elevation data and the poor distribution of the $0.5 \mathrm{~m}$ spaced contour lines. In order to overwhelm the problem we decided to reconstruct $0.5 \mathrm{~m}$ spaced contour lines for the entire urban center by interpolating selected elevations. In addition, taking into account the non-homogeneous distribution of local elevations, we also carried out a detailed GPS survey in the historical centre to provide further elevation data in some poorly constrained sectors. Once derived the spatial distribution of $0.5 \mathrm{~m}$ spaced contour lines, we interpolated them by means of the Topo to Raster tool of ArcGIS 10.1 and, finally, obtained a $0.5 \mathrm{~m}$ DTM for the entire urban area. We used this very detailed DTM to derive a slope map (Figure 2) and a curvature map aimed at the individuation of topographic elements of anthropic or natural origin that can be related to the archaeological findings.

\subsection{Results}

The investigated area is characterized by slope gradients ranging from $0^{\circ}$ to $64^{\circ}$ (Figure 2). Particularly, the summit surface that hosts the historical centre is largely characterized by very low gradients $\left(\max .6^{\circ}\right)$ but also by the presence of several meters high scarps that locally interrupt the gentle sloping of the surface towards SW as evident both on the slope map and on the $0.5 \mathrm{~m}$ DTM.

The adjacent slope portions have overall gradients form 6 to $64^{\circ}$. Slope peaks (ranging between $40^{\circ}$ and $50^{\circ}$ ) match with scarps bordering anthropic terraces and highest gradients characterize the scarps bordering the travertine outcrops (see Section 3).

Furthermore, starting from the outcropping wall structures, slope features along with the distribution of contour lines on the $0.5 \mathrm{~m}$ DTM allowed for the recognition of several buried or partial eroded wall fragments.

Further information on the local morphological setting was extracted from the curvature map. This map shows the presence of both concave and convex slope portions that correspond to areas affected respectively by erosion and deposition, especially by landslides or colluviation that have be considered in relation to the possible identification of archaeological finds.

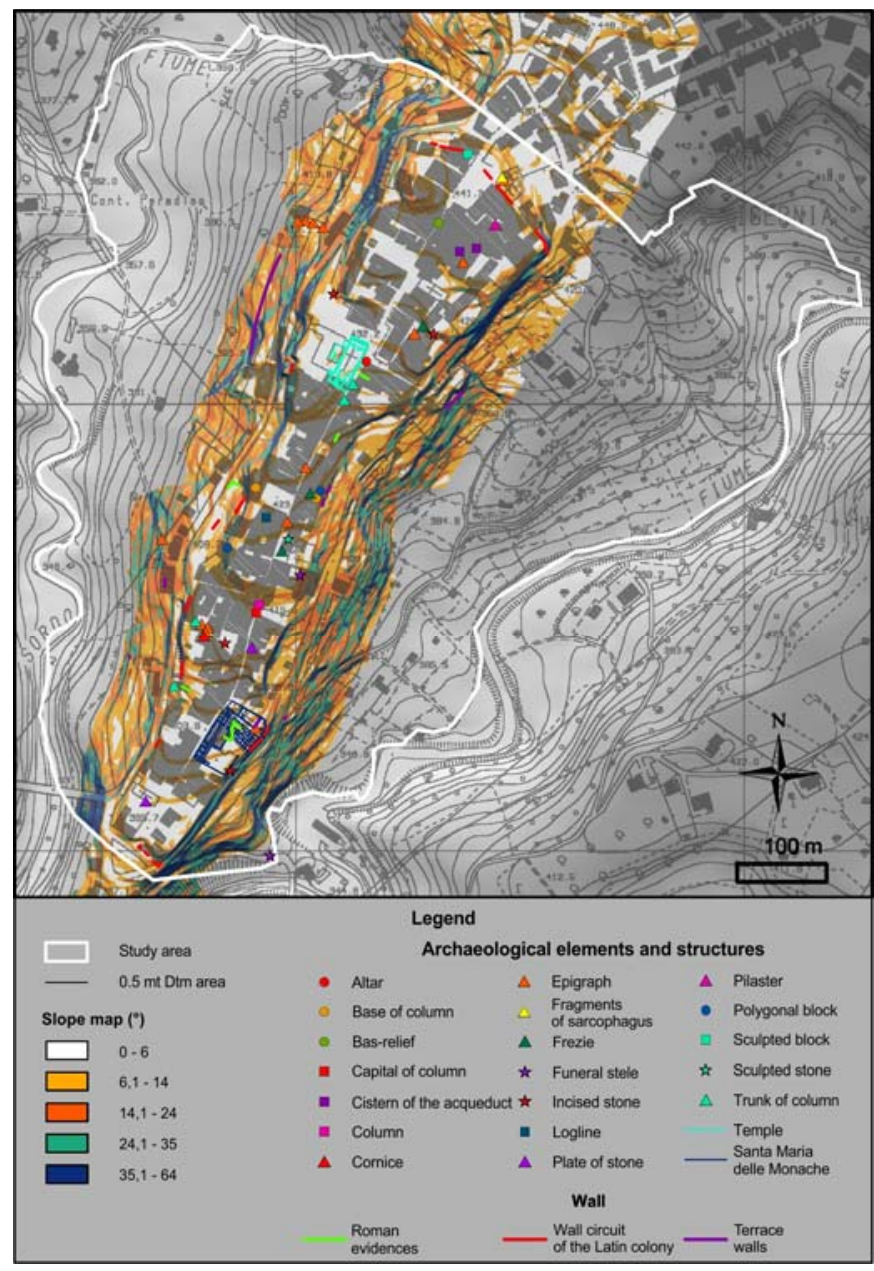

Figure 2. Relation between slope features of the historical centre of Isernia and the distribution of archaeological evidences.

\section{GEOLOGICAL AND GEOMORPHOLOGICAL ANALYSES}

\subsection{Methods}

The geological and geomorphological analyses has focused on the chrono-stratigraphy of the local Quaternary succession and the characterization of the geomorphic and sedimentary events that have affected the area of Isernia.

Starting from the literature data on the Isernia basin [13], [14] and the field data acquired during a recent project on the seismic microzonation of the Isernia province [15], we carried out a stratigraphic analysis of ca. 25 boreholes and a detailed geomorphological study.

We compared the obtained local chrono-stratigraphy with the one reconstructed at Isernia La Pineta [16] and recently dated by Coltorti et al. [14] to 600000 years.

This approach allowed us to elaborate a new geological map at scale 1:5,000 of Isernia, extremely useful for understanding the subsurface lithofacies distribution and supporting several archaeological interpretations (Figure 3).

Several geological cross-sections were constructed in order to illustrate the local chrono-stratigraphic sequence and show their relationships with the distribution of archaeological findings on the surface (Figure 4). 


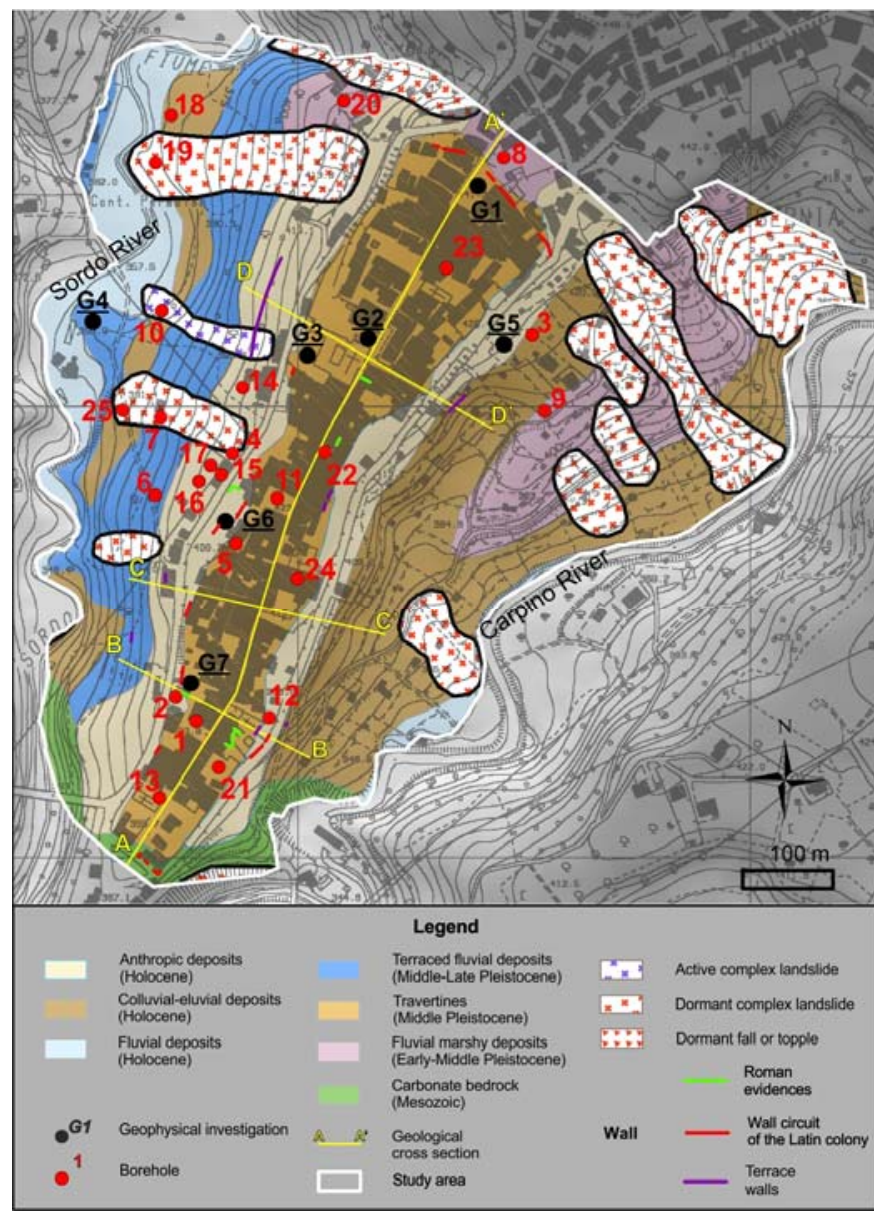

Figure 3. Geological map of the historical centre of Isernia.

\subsection{Results}

Isernia is a town located in the northern sector of the Southern Apennines, a NE verging fold and thrust belt formed during the Neogene due to the collision between the European and the Adria plates [17]. This sector of the chain has been affected by regional uplift and by NE-SW oriented extensional tectonics since the Middle Pleistocene [18] that led to the formation of high mountainous to hilly reliefs, mainly made of Meso-Cenozoic carbonate rocks, and of several intermontane depressions, then filled up by tens to hundreds of meters thick sequences of lacustrine and fluvial-marshy deposits [19].

The area of Isernia falls within one of these intermontane depressions which is called the Isernia Basin. The town is located at a medium elevation of ca. $440 \mathrm{~m}$ a.s.l. on a major remnant of a fluvial terrace that forms a narrow NNE-SSW elongated ridge degrading southwestwards from $465 \mathrm{~m}$ to 358 $\mathrm{m}$ a.s.l. and confined by the two narrow, about $50 \mathrm{~m}$ deep incisions of the Sordo and Carpino rivers (Figure 3).

The pre-Quaternary substratum is made of limestones and marls, locally intercepted by the Carpino and Sordo incisions along the southwestern margin of the ridge. The fluvial terrace is made up of lacustrine clays with thin layers of gravels and sands referred to the Lower Pleistocene according to the reversed paleomagnetic data [20] and to the terrestrial malacofaunal assemblage [21], followed by fluvial and marshy travertines made of alternating calcareous sands, phytoclastic, phytohermal and stromatolithic layers with interbedded thick paleosols and lacustrine clays. On top of the travertines, thin paleosols, fluvial-marshy and tephra layers are locally present. At the Paleolithic site of Isernia La Pineta, several Ar/Ar datings on tephra layers allowed for constraining the upper part of the fluvial-marshy succession to the Middle Pleistocene (up to ca. 0.5 Ma BP) [17].

1 to $10 \mathrm{~m}$ thick colluvional and anthropic deposits characterize several areas located close to the edges of the ridge and on the slopes bordering the ridge. The slopes are also characterized by the presence of landslides, generally dormant and only in some cases still active.

Geological-geomorphological surveys carried out specifically in the urban and peri-urban areas of the historical centre of Isernia have allowed identifying the correlation between

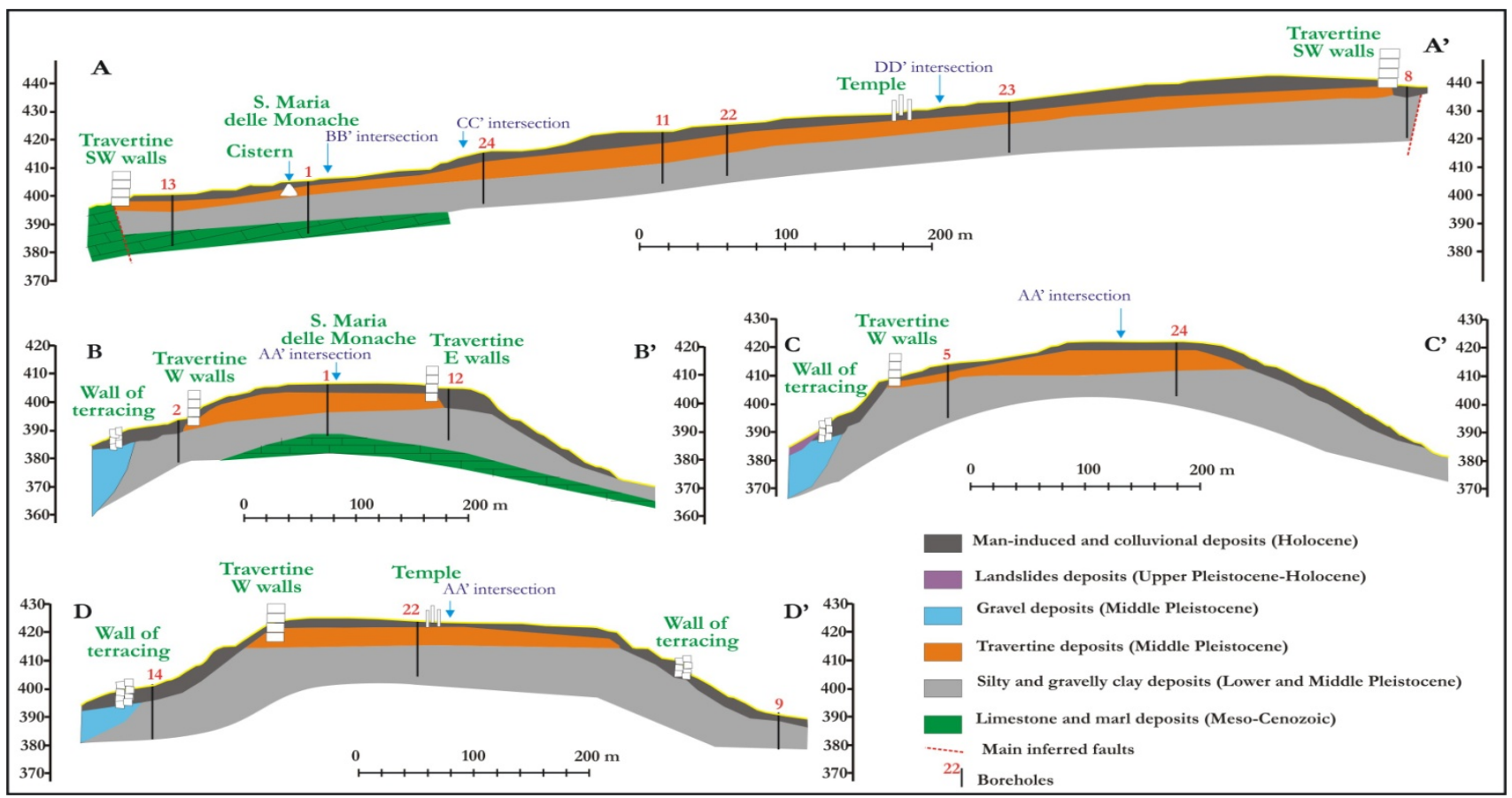

Figure 4. Geological cross sections of the Isernia historical centre. For traces see Figure 3. 
archaeological finds and outcropping lithologies that is shown in the schematic geological cross-sections of Figure 4. Most of the archaeological finds were found within the urban area of Isernia directly on top of the travertine units, generally covered by 2 to $3 \mathrm{~m}$ thick anthropic deposits. Alike, the walls of the Latin circuit were built on top of the travertines along the border of the elongated ridge, probably to improving their stability and their defensive role. The circuit walls are locally missing, especially in correspondence of some concave forms of the ridge borders that are interpreted as remnants of detachment niches of historical landslides.

Most of the terrace walls were found, instead, just outside the Latin walls, where anthropic and colluvial deposits crop out. These walls were built in order to reduce the slopes of the valley flanks and, therefore, soil erosion and landslides on clayey slopes.

In several sectors in which colluvial deposits crop out, archaeological finds are very rare or lacking. This can be explained considering that these areas were subjected to alternating phases of erosional and depositional processes which have reduced the probability to preserve man-made artefacts or to find them on the surface. Finally, the presence of a thick layer of anthropic deposits on the top of the surface and along its borders allow supposing that the archaeological potential of the historical centre of Isernia is mainly concentrated here.

\section{ARCHAEOLOGICAL SURVEY}

\subsection{Methods}

A non-invasive method of archaeological surface survey was adopted in order to reconstruct the ancient urban and periurban layout through the evaluation of the presence and concentration of archaeological materials within these areas.

In the historical centre (Urban Survey), where the strong urbanization greatly hinders the discovery of new archaeological elements, a detailed census of all known evidences was carried out. All typologies of finds (epigraph, bas-relief, altar, column, funeral stele, etc.) and structures (cistern of the aqueduct, fragments of the wall circuit, terrace walls, temples, roman walls, etc.) were censured using a specific schedule (Figure 5) and located in the Visibility and Concentration Maps (Figures 6 and 7). Particularly, this schedule contains information about the location, dimensions, age, type of material, state of conservation, manufacturing, construction type, function of

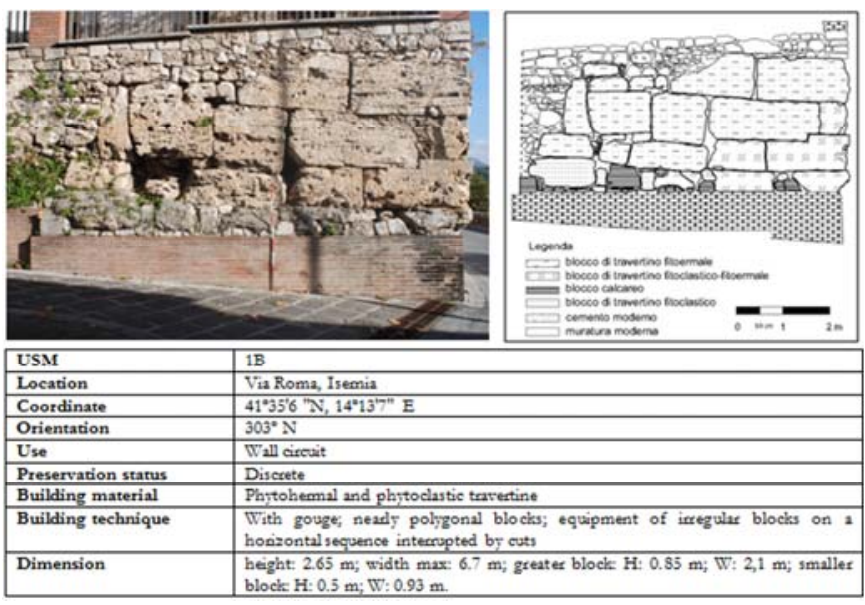

Figure 5. Example of the schedule used for the census of archaeological. individual parts of the walls, stratigraphic relations, photo, relief and description of recorded archaeological elements.

Outside the urban area (Peri-Urban Survey), archaeological data have been collected using the intensive off-site field survey strategy [22] by performing parallel strips approximately one meter spaced. For each investigated cadastral unit, the geomorphologic and geological features, vegetation type, visibility of the surface (null, insufficient, medium, good and very good) along with the type, number and concentration (number of finds $/ \mathrm{m}^{2}$ ) of archaeological finds have been registered.

Overall, an area of about 530,000 $\mathrm{m}^{2}$ has been covered by prospection and acquired data have been stored in the GIS project.

\subsection{Results}

A Visibility Map and a Concentration Map have been created, for the historical centre of Isernia and its peri-urban area.

The Visibility Map (Figure 6) shows the location of the main archaeological findings of the urban area and the different degree of visibility of the terrain during the peri-urban survey: $65 \%$ of the surveyed area is characterized by inaccessibility due to a dense vegetation cover or to modern alterations; $8 \%$ of the investigated area is off limit and foreclosed from access due to the presence of fences of private homes; $27 \%$ of the investigated area has medium or good conditions of visibility. Nevertheless, the lack of archaeological documentation in areas with null visibility does not preclude the presence of possible sites.

The Concentration Map (Figure 7) shows both the location of the main archaeological findings within the urban area and the density of finds for each cadastral units in the peri-urban area along with the location of most important sites (S1-S9). All archaeological evidences found during the peri-urban survey were scheduled, photographed, studied and classified. In particular, site S1 (Figure 7) provided the highest percentage of findings ( $53 \%$ of the total amount). The analysis of materials allowed to identify several types of ceramic: undecorated ceramic vases (29 \%), black painted ceramic (23\%), undecorated fire vases $(16 \%)$ and glazed ceramic $(14 \%)$; the remaining part of materials $(18 \%)$ is represented by metals, red painted ceramic, enameled ceramic, glass, terra sigillata, incised pottery, engobe ceramic and proto-maiolica pottery.

\section{GEOPHYSICAL PROSPECTIONS}

\subsection{Methods}

Geophysical prospections were carried out in urban sectors in which the possible detection of archaeological remains was impeded by the presence of anthropic structures. Geophysics and archaeologists operated in full synergy by calibrating the procedures of intervention and taking into account all the needs of the research. Geophysical prospections were programmed in accordance with the archaeologists, assuming the type, size and depth of the probable findings in the subsurface and considering the logistics of the survey area and the nature of the subsoil in order to define the best strategy for its investigation.

\subsubsection{Electrical Resistivity Tomography (ERT)}

ERT is one of the most reliable prospecting tools in the field of Cultural Heritage, thanks to the technological and methodological developments of the last years which have made this method a fast target-oriented one. The resistivity 


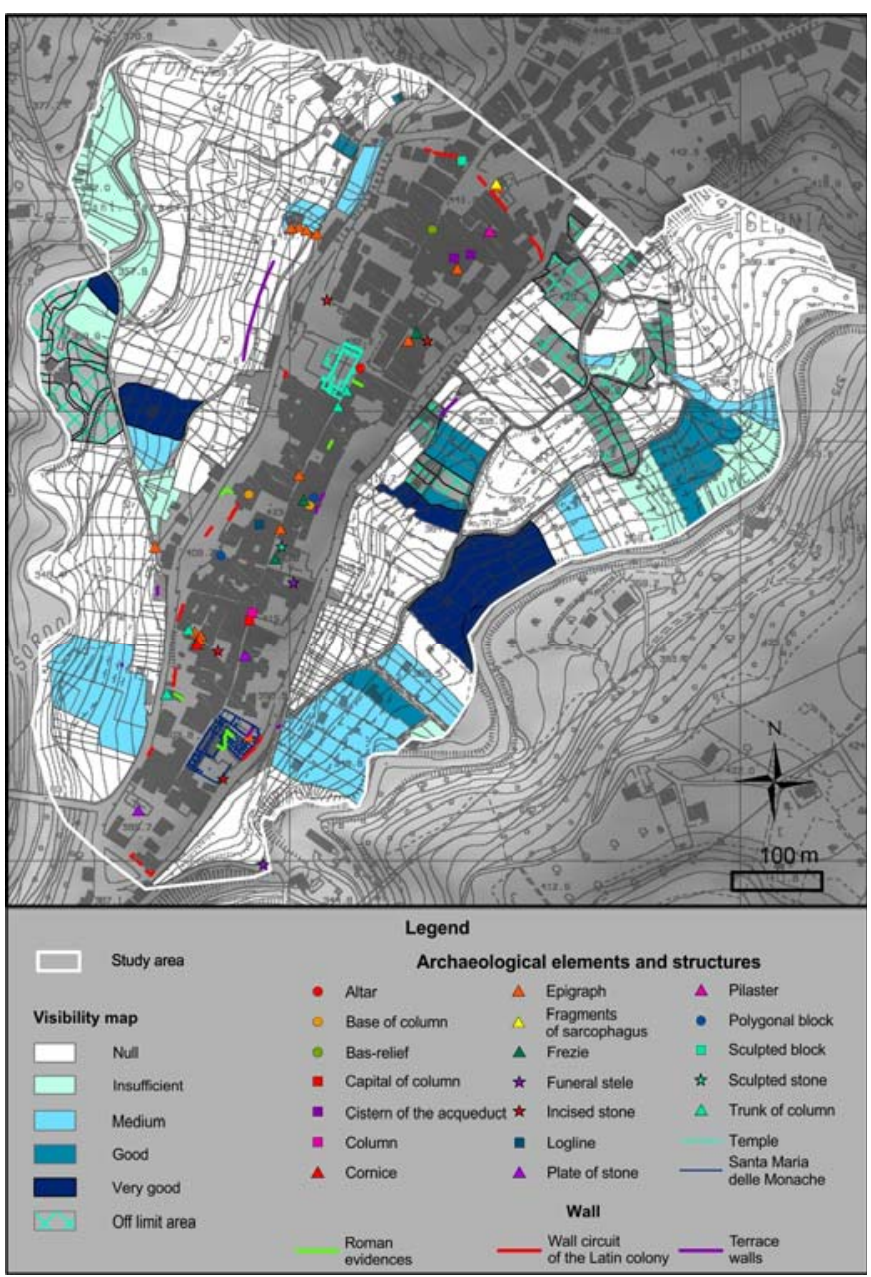

Figure 6. Visibility Map of the surveyed area.

parameter, on which the method is based, has a variability so high as to allow the distinction of the great majority of the structures and elements of archaeological and architectural interest from the hosting material.

In order to estimate the intrinsic resistivities of the media composing the subsoil under investigation, a four-electrode array is applied. Two electrodes, conventionally indicated by the letters A and B, are used to inject a pre-selected current into the ground and two other electrodes, indicated by $\mathrm{M}$ and $\mathrm{N}$, are used to measure the resulting potential differences on the ground surface. An apparent resistivity parameter is determined at each position of the array by multiplying the measured resistance opposed by the ground to the current flow. However, due to the spreading of the exciting current from the current electrodes all over inside the solid half-space, the apparent resistivity generally differs from each of the intrinsic resistivities because, in an inhomogeneous subsoil, the global influence of different volumes with different intrinsic resistivities is detected. The result is that the apparent resistivity is a volumetric average of all of the intrinsic resistivities underground, calculated through a complex weighting function dependent on the four electrodes device and how it is used.

During 3D ERT data acquisition, a multiple set of parallel profiles were realized creating a grid pattern.

Each profile was arranged on the ground and a battery of galvanic contacts placed at regular steps to sense the local nature of the subsoil. The MAE A3000 resistivity meter (www.mae-srl.it) was used. The dipole-dipole (DD) sourcereceiver coupling was implemented as measuring modality with

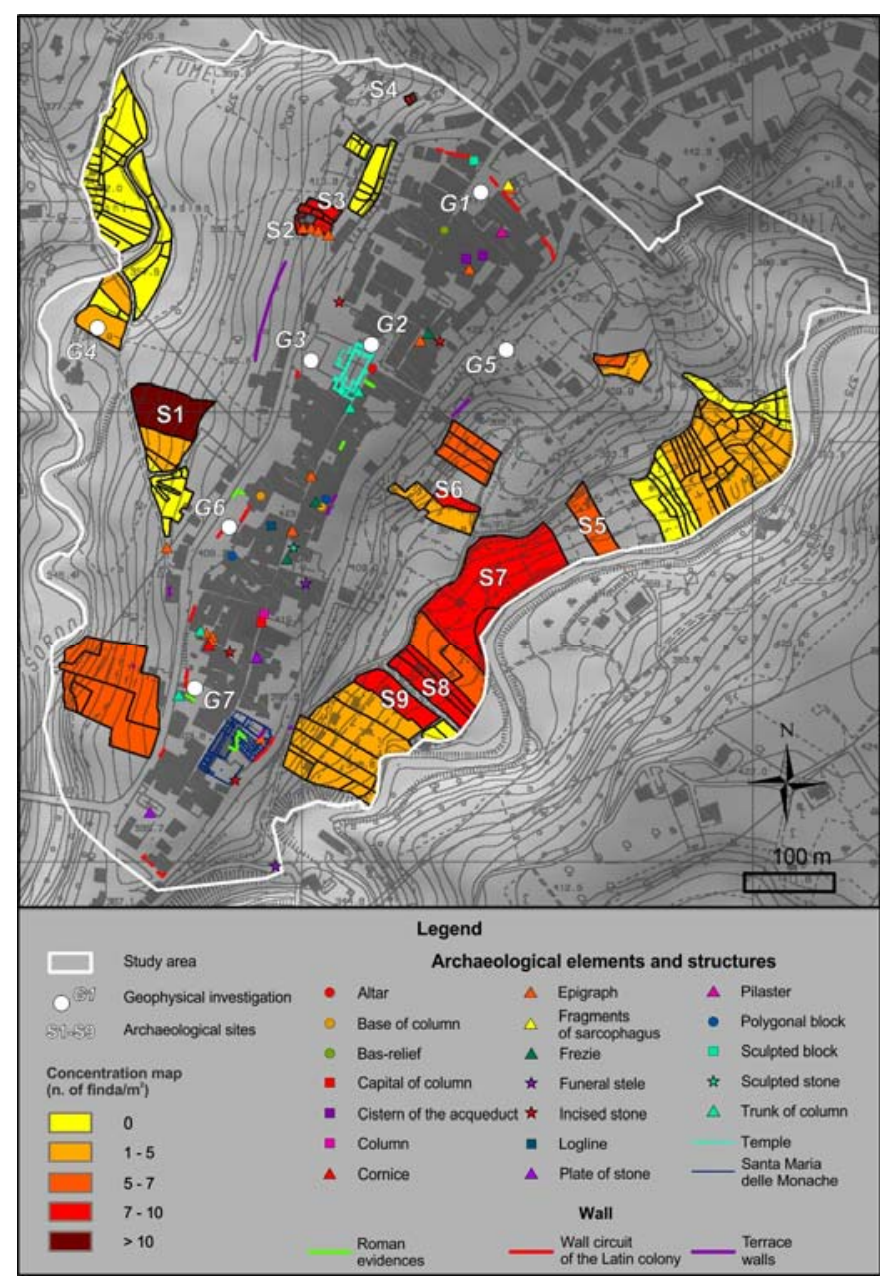

Figure 7. Concentration Map of the surveyed area and map of archaeological finds.

a distance between electrodes equal to $1 \mathrm{~m}$ in order to better delineate lateral resistivity changes.

Subsequently, by combining data of multiple sets, a 3D tomospace of the investigated area was obtained. The consequent 3D distribution of the apparent resistivity at the datum points was imaged by drawing sequences of horizontal slices at increasing depths. In order to remove corrupting effects and model the survey targets as accurately as possible, we concerted apparent into real resistivities by using the probability-based ERT inversion (PERTI) method [23] which is a fast, reliable inversion tool directly derived from the principles of the probability tomography [24]. The main features of this method are: unnecessity of a priori information; full, unconstrained adaptability to any kind of dataset, drastic reduction of computing time of even two orders of magnitude with respect to standard deterministic inversion tools, independence from data acquisition techniques and spatial regularity, capability to resolve complex continuous resistivity variation. Many field cases were dealt with using this approach [25]-[30], and in all cases the procedure proved a reliable tool for the most probable locations of the sources of the measured apparent resistivity anomalies to be highlighted at the appropriate depths.

\subsubsection{Ground Penetrating Radar (GPR)}

The use of GPR for the study of archaeological contexts is possible because human activities inevitably alterate the natural 
cycle of soil formation, produce physical and chemical changes within the soil and led to the accumulation of cultural remains. Such alterations can be detected by transmitting an induced electromagnetic field (reflection, diffraction) into the ground that is then viewed through a contour map of the subsoil. Certain anomalies shown in such maps reflect changes of basic properties of the electromagnetic field, in its conductivity $(\sigma)$, electric permittivity $(\varepsilon)$ and magnetic permeability $(\mu)$; parameters that are interrelated and therefore correspond to alterations caused by accumulations of objects and/or are products of the interfaces between different soil types. The factors that affect system performance, in terms of detection capabilities of the existing targets, are above all the electromagnetic properties of the medium propagation that determine the depth of investigation reached which therefore varies from point to point. However, as medium mitigation is a function of frequency radiated, the use of low-frequency antennas can generally extend the depth of penetration of GPR signals but can also generate the loss of resolution.

Two parameters are measured during data acquisition: the time in which the electromagnetic wave fulfils the path transmitter antenna-discontinuity-receiver antenna (two way time) and the amplitude of the wave.

The two way time $t$ depends on the velocity $v$ with which the wave spread into the materials and gives information about the depth $h$ of the reflectors, according to the equation $t=2 h / v$ from which $h$ can be easily derived: $h=v t / 2$.

The amplitude (A) represents the amount of energy that returns to the surface and depends on the energy of the transmitted wave, on how much of it is dissipated along the path and on the contrast in the electromagnetic properties of the materials that determine the reflection surface

For GPR measurements, an IDS RIS-K2 Georadar, equipped with a multi frequency antenna TRMF (600-200 $\mathrm{MHz}$ ), was used. All radar reflections were recorded digitally in the field as 16 bit data and 512 samples per radar scan. The spacing between parallel profiles at the site was $0.5 \mathrm{~m}$ and they were collected alternatively in opposite directions with angles of 90 degrees in the survey grids. Radar reflections on each line were recorded at 40 scan s$^{-1}$ (1 scan approximately corresponds to $0.04 \mathrm{~m}$ ).

Standard bi-dimensional radargrams relative to single transects were processed through the IDSGRED software.

Band pass filters and the Gain Control were applied in order to remove high and low frequency anomalies that occurred during the data acquisition, normalize the amplification and remove reflections generated by noise due to the different signal attenuation [31]. Thus, using a sequence of parallel lines, a three-dimensional matrix of averaged square wave amplitudes of the return reflection was generated and time-slices were realized for various time windows. Data were then gridded using a moving average routine and a radius of interpolation equal to $1 \mathrm{~m}$. The abnormalities seen in these representations depict the spatial distribution of the amplitudes of the reflections at specific depths within the grid. Within the slices, low amplitude variations express small reflections from the subsurface and, therefore, indicate the presence of fairly homogeneous material. High amplitudes denote significant discontinuities in the ground and often evidence the presence of buried objects. A definite change between high and low amplitudes may indicate the presence of a buried interface between two media.

\subsection{Results}

Prospection were carried out in seven unexplored sites (G1G7 in Figure 7), five of which are located within or immediately outside the walls (G1, G2, G3, G6 and G7) the other two (G4, G5) in the peri-urban territory.

Taking into account the features of the sites and the environment in which the archaeological structures are inserted, alternatively the non-invasive Electrical Resistivity Tomography (ERT) and the Ground Penetrating Radar (GPR) technique were implemented with the purpose to obtain a 3D reconstruction of the buried structures.

3D ERTs were realized in sites G3, G4, G5, G6 and G7, while GPR surveys were carried out in sites G1 and G2. Particularly, the GPR applications were chosen for those sites in which the surfaces are covered by modern pavements that could render not much reliable the results of other types of geophysical prospections.

Site G1 is located in Piazza Celestino V. Here, excavations brought to light a section of the walls of the Roman colony [32]. The purpose was to verify the existence of other archaeological structures still buried beneath the pavement of the modern square. Two GPR survey areas were realized: the first one was arranged within the eastern portion of the excavation trench, parallel to the ancient wall, through the realization of 8 profiles, spaced $0.5 \mathrm{~m}$ and with a length of 20 $\mathrm{m}$; the second one, composed by 18 lines, spaced $0.5 \mathrm{~m}$ and ca. $22 \mathrm{~m}$ long, was placed in the north-western sector of the excavation trench.

In Figure 8, an example of raw data (a) and the corresponding processed section (b) is presented. The position of the line is indicated in Figure 9c with a blue arrow. The section enhances a high level of noise due to the presence of an iron grid put under the pavement. As the nature of the materials traversed by the electromagnetic waves is not known and, consequently, the speed of propagation of electromagnetic waves in them is not known, the time scale was not converted in depth scale through the "best fitting" operation of the hyperbolas of radargrams due its high margin of arbitrariness.

Figure $8 \mathrm{c}$ shows the resulting slice of site G1 expressed in the time window from 9 to 24 ns (two way time). On the east side of the trench excavation, the presence of small straight anomalies have led to hypothesise the continuation of some medieval walls leaning on the blocks in polygonal technique. In the northern part of the wall, high amplitude spots seem to attest the presence of the continuation of the wall circuit within the subsoil. On the west side of the slice two segments forming an angle of $90^{\circ}$ are observable and could correspond to the corner of a buried structure.

Site G2 is located in Piazza Andrea d'Isernia, in the area with high archaeological potential that surrounds S. Pietro Cathedral. 20 GPR profiles, spaced at $0.5 \mathrm{~m}$ and about $60 \mathrm{~m}$ long, were acquired. Figure 9 shows the resulting slice expressed in the time window from 9 to $24 \mathrm{~ns}$ (two way time). The most interesting results were obtained in front of the entrance of the modern church where two anomalies with high amplitude values and regular shapes are evident. They might be attributable to buried archaeological structures related to the temple of the colony brought to light the podium of the temple of the colony dating to the third century BC.

Site G3 is placed in the garden of the bishop's palace. The purpose was to prove the existence of buried structures connected with the western temple. 

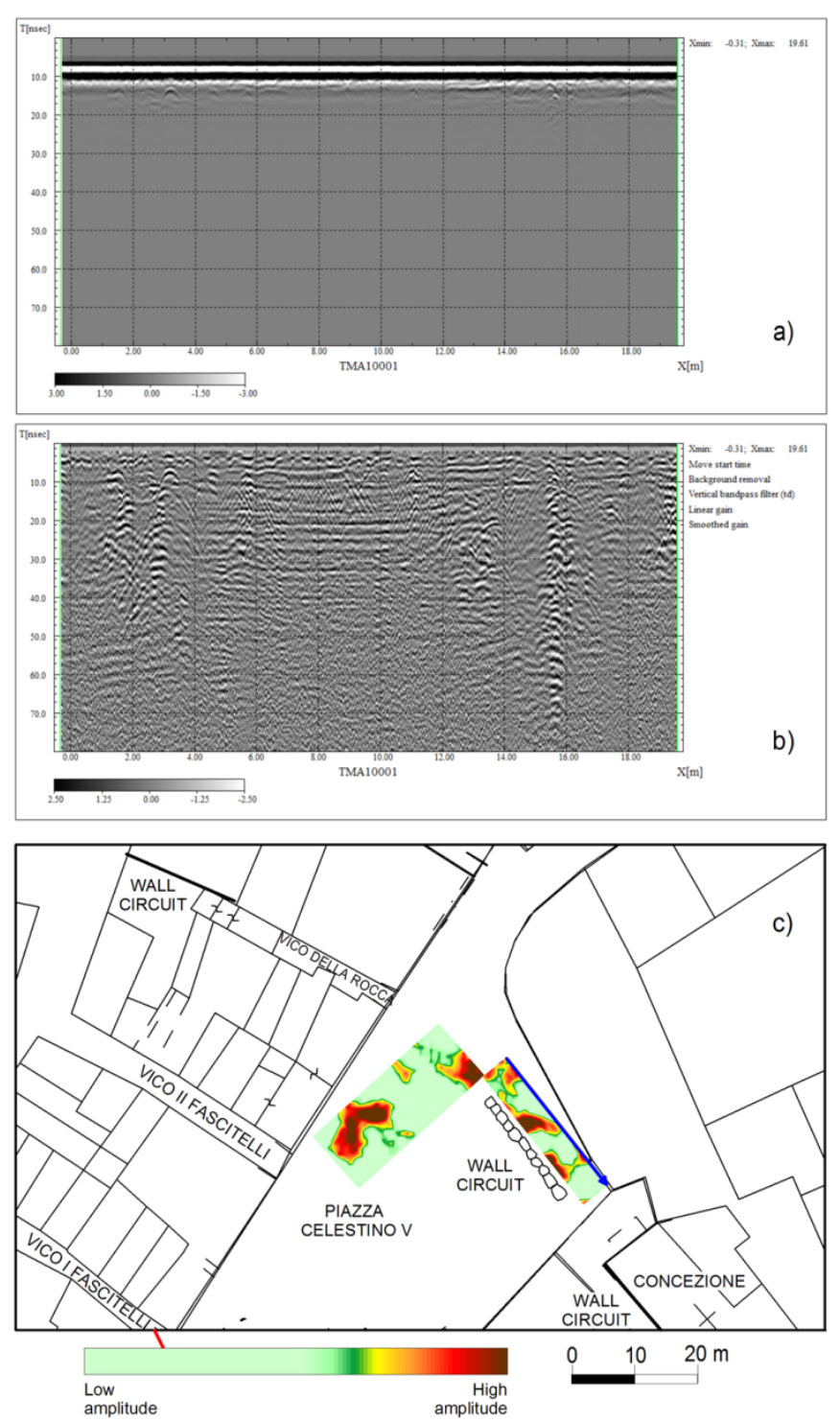

Figure 8. G1 site: an example of raw data radargram (a), the same section after the filtering (b) and time slice in the time window from 9-24 ns (c). The blue arrow indicates the position of the analyzed section.

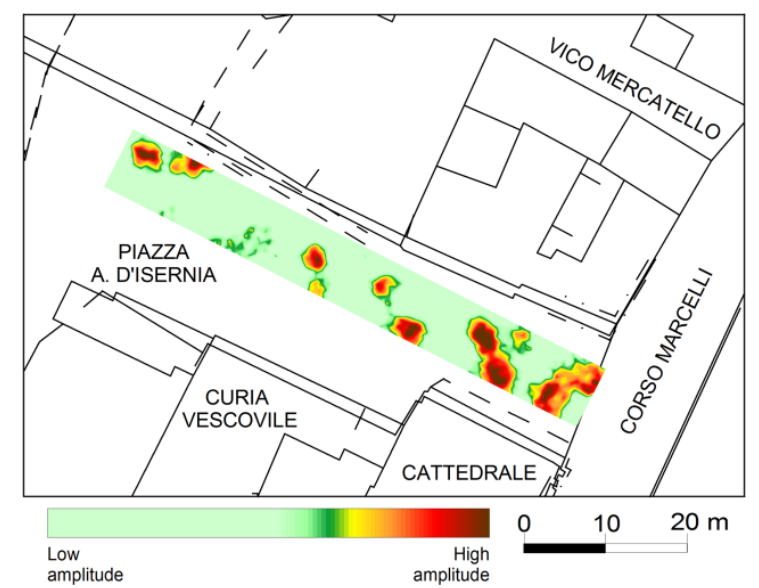

Figure 9. G2 site: time slice in the time window from 9-24 ns.

ERT survey was conducted in two areas, A and B (Figure 10), through twelve profiles respectively 10 and $16 \mathrm{~m}$ long. In both areas, the space line was established to $1 \mathrm{~m}$.

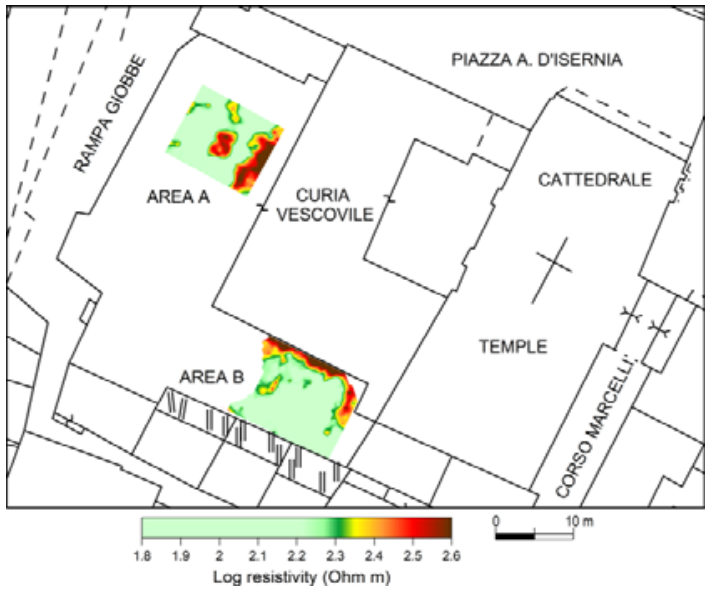

Figure 10. G3 site: ERT relative to $1 \mathrm{~m}$ depth.

In area A (Figure 10), the ERT relative to $1 \mathrm{~m}$ depth highlights a considerable rectangular anomaly and a high resistive spot, located at the centre of the surveyed area, with the shape of a rectangle of 2.5 per $4 \mathrm{~m}$. Considering the small size of this anomaly, it can be likely interpreted as the image of an altar or the base of a statue. In area $\mathrm{B}$, a high resistive anomaly of about $10 \mathrm{~m}$ in length was identified. It could be interpreted as a portion of a public building of significant size. A state of high conductivity prevails in the whole area and could be the evidence of an open area, probably paved, in complete synergy with the urban planning of the colony.

Site G4 is located outside west to the urban area (Figure 11), in locality Paradiso, where a particular soil anomaly with the
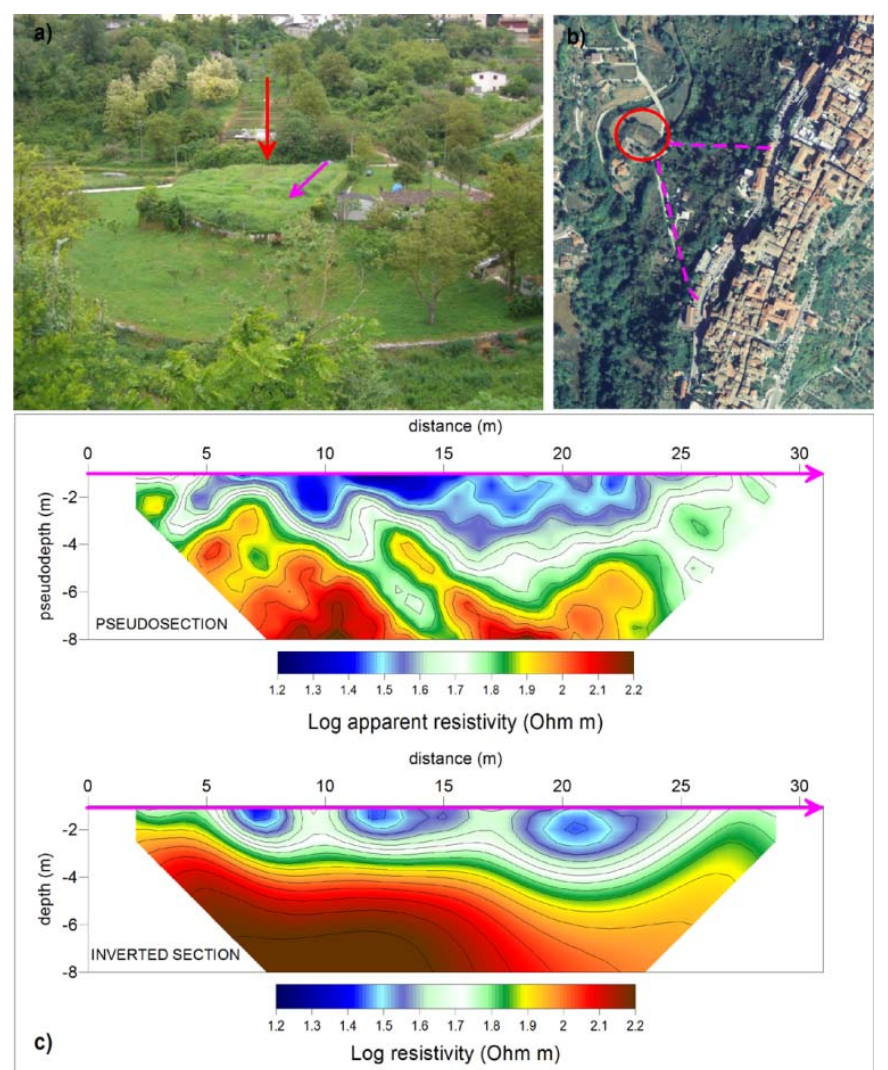

Figure 11. G4 site: view of the semicircle structure indicated with a red arrow (a); location of site $\mathrm{G} 4$ and hypothetical roads linking the site to the sub-urban colony (b); example of pseudosection and inverted section acquired in the point indicated with a pink arrow in figure (a). 
shape of a perfect semicircle (radius of $25 \mathrm{~m}$ ) was identified. It is located on a mezzanine floor over the surrounding land (Figure 11a) at about $150 \mathrm{~m}$ from the circuit perimeter of the colony (Figure 11b). The purpose of the geophysical survey was to test if this element is a natural landform (Sordo River fluvial terrace), an anthropic structure or an anthropic structure built on the top of the fluvial terrace.

About 5500 datum points of apparent resistivity were collected in order to produce a 3D representation of the analyzed volume of subsoil. In Figure 11c a pseudosection and an inverted section are reported as example. The position of the shown profile is indicated with a pink line in Figure 11a. For better disclosing the nature and the shape of the resistive structures, a smaller area (the southeastern portion of the semicircular area) was contoured using the mean resistivity value as the cut-off resistivity. All isosurfaces matching with resistivities below the cut-off resistivity were blanked (Figure 12a). This presentation presumes the probably presence of an articulated structure on split levels. In the shallowest horizontal real resistivity slices at $4 \mathrm{~m}$ depth, a high resistive anomaly appears near the edges of the semicircular area and a low resistivity situation is visible in its central portion (Figure 12b). The geophysical results suggest the presence of a semicircular public building. A direct archaeological excavation should verify its precise nature.

Site G5 is located in an area where a Roman wall was brought to light and partially excavated during the construction of the municipal parking lot. The objective of the survey was to better delineate the still buried structures. An area of about $1300 \mathrm{~m}^{2}$ was covered by numerous ERT profiles with different length and spaced $1 \mathrm{~m}$ apart.

The tomography relative to $0.5 \mathrm{~m}$ depth (Figure 13) shows in the southwestern part of the survey area a high-resistive anomaly that can certainly be interpreted as the continuation of the wall structure. In the southeastern part, a high resistive anomaly with a rectangular size (about $20 \times 5 \mathrm{~m}$ ) and the same orientation as the previous one emerged.

Site G6 is situated on the east side of Via Occidentale. Here, in the 1980 s a wall, perpendicular to the road, with a length of about $7 \mathrm{~m}$, and a semicircular collapsed structure were revealed by a test excavation a few meters beneath the current ground level. The survey was realized in the southern part of the area occupied by the semicircular structure in order to better delineate the building. 8 ERT profiles, spaced $1 \mathrm{~m}$ apart and 30 $\mathrm{m}$ long, were acquired.

The tomography relative to $0.5 \mathrm{~m}$ depth (Figure 14) has evidenced a high resistive anomaly that appears to be the exact continuation of the wall emerged from the test excavation. In the southern portion, it is possible to hypothesize a probable environment whose contours appear in synergy with the known archaeological structures.

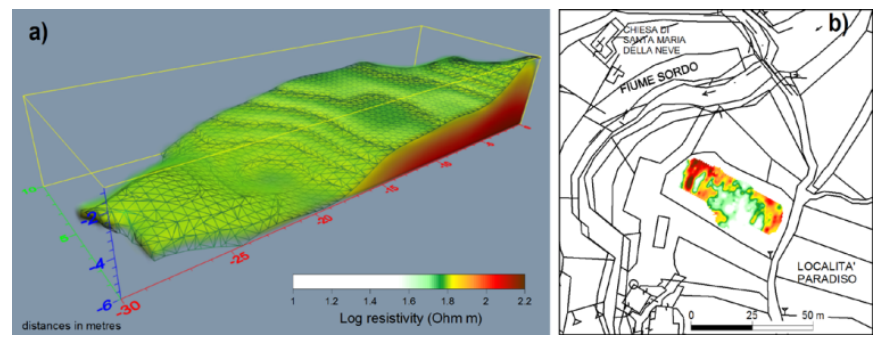

Figure 12. G4 site: 3D representation of the southeastern portion of the semicircular area (a); ERT relative to $1 \mathrm{~m}$ depth (b).

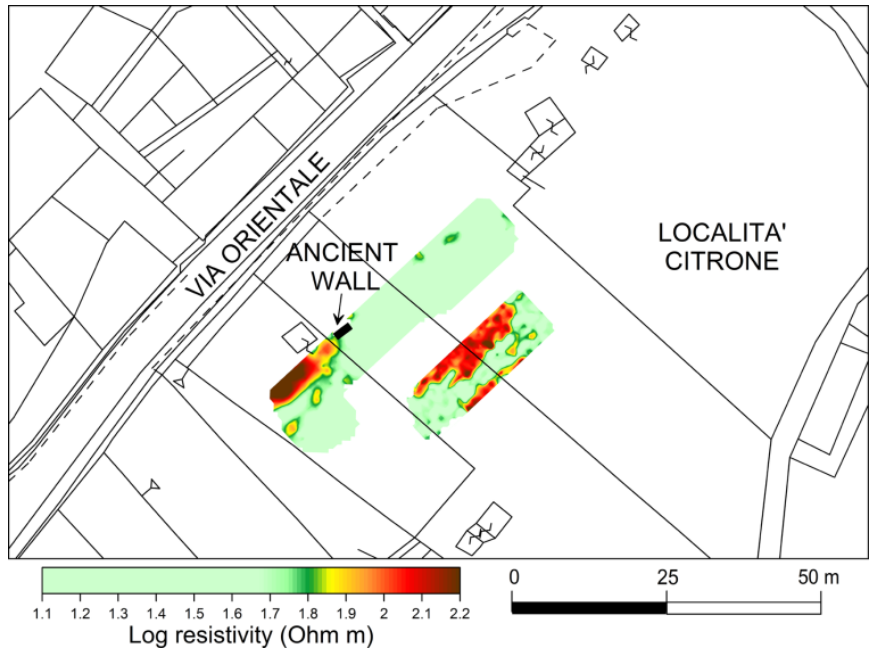

Figure 13. G5 site: ERT relative to $0.5 \mathrm{~m}$ depth.

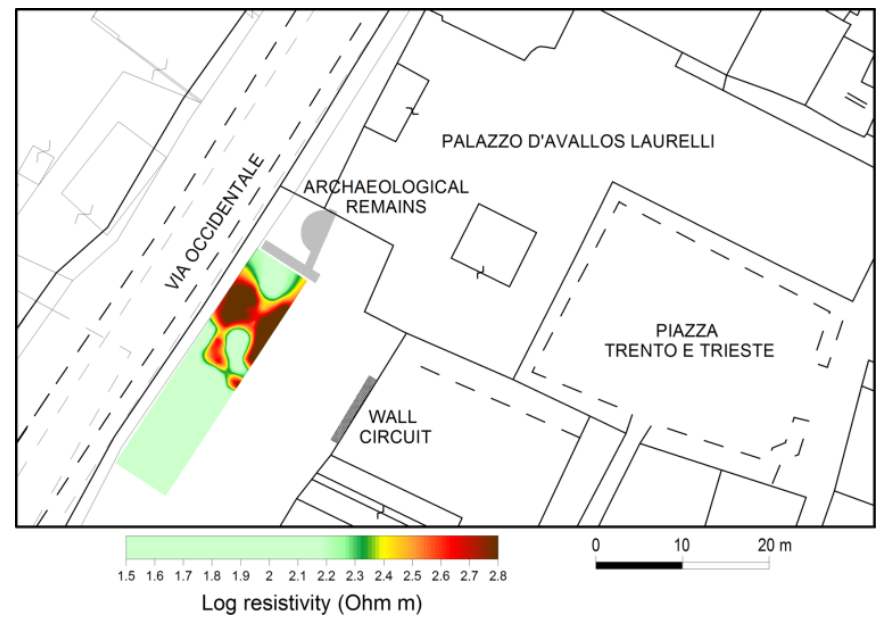

Figure 14. G6 site: ERT relative to $0.5 \mathrm{~m}$ depth.

G7 survey is located in a private property where several aligned limestone blocks emerged in 2009 during the restoration of the house. This structure of considerable size (about $10 \mathrm{~m}$ in length) is built with polygonal limestone blocks but is perpendicular to the outer wall, and likely can be interpreted as a urban terrace wall. The survey was realized in the free space around it in order to detect the probable presence of other walls within the soil. An area of about $200 \mathrm{~m}^{2}$ was covered by numerous ERT profiles of different lengths and spaced $1 \mathrm{~m}$ apart.

In the eastern part of site $G 7$, the tomography relative to 1 $\mathrm{m}$ depth (Figure 15) has shown some anomalies with regular shapes and perpendicular to the walls of the circuit. To the west, there is a significant anomaly with similar orientation to the archaeological structures visible in the area.

\section{DISCUSSION AND CONCLUSIONS}

The integrated geo-archaeological study performed in the area of Isernia allowed to draw up a new archaeological map shown in Figure 16. This map shows the types and location of all archaeological elements and structures censured in the urban and peri-urban areas of the historical centre of Isernia along with new elements derived from archaeological and geophysical surveys (Figure 16). 


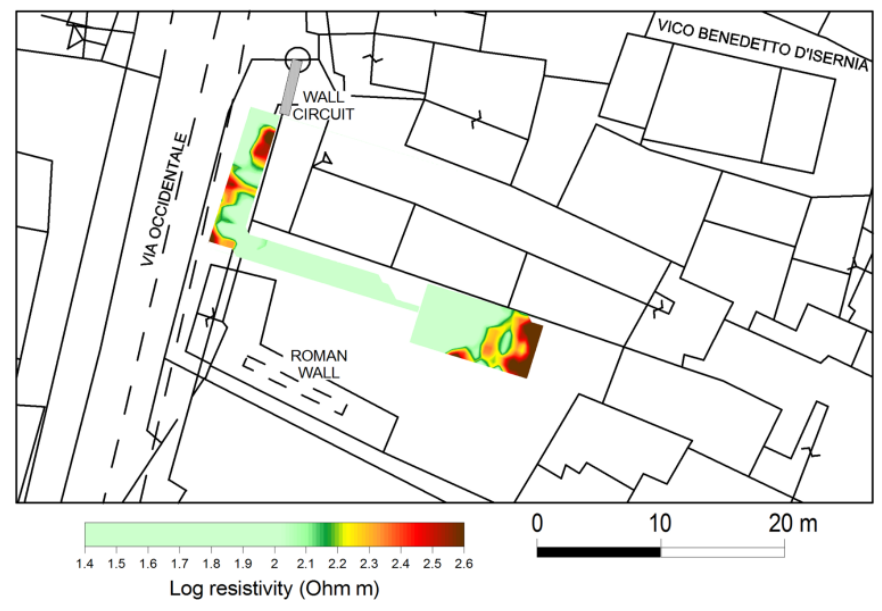

Figure 15. G7 site: ERT relative to $1 \mathrm{~m}$ depth.

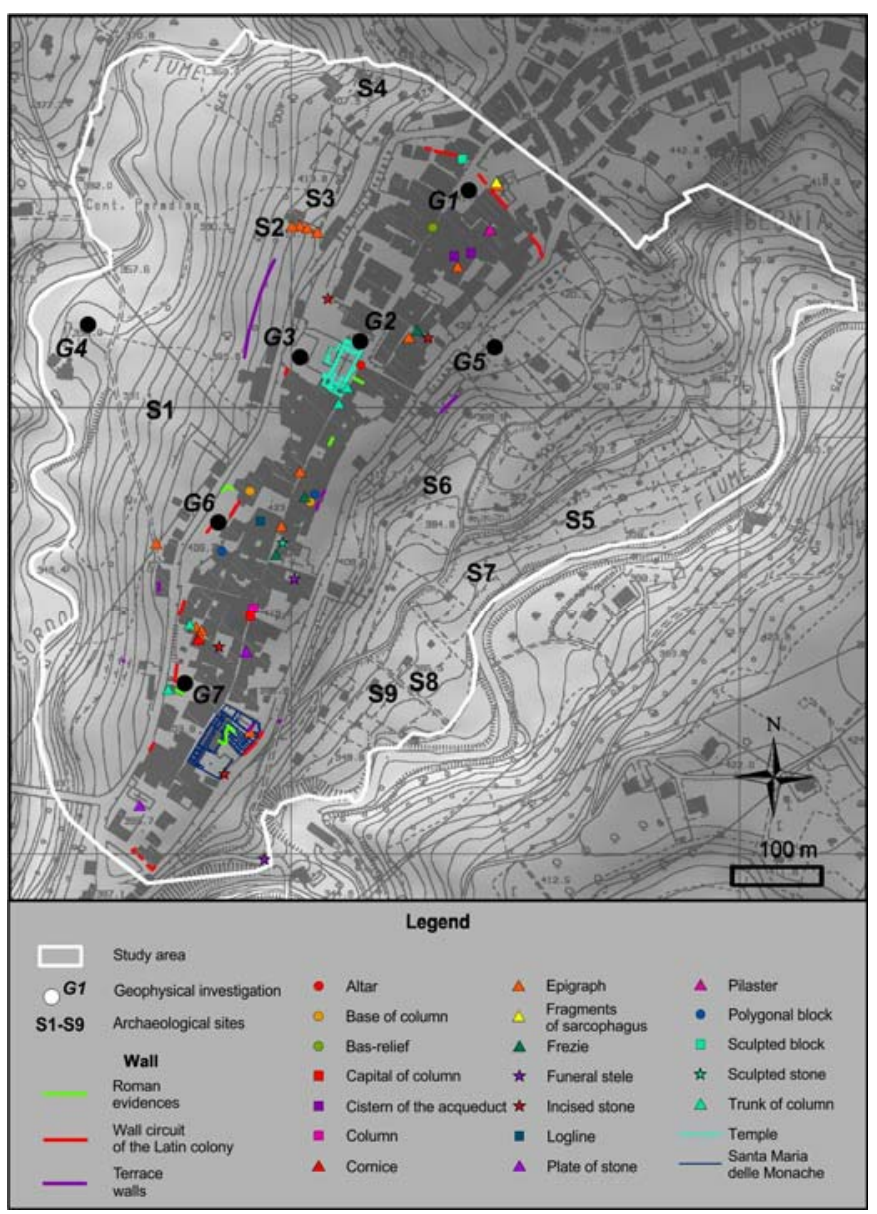

Figure 16. Map of the archaeological evidences of the historical centre of Isernia and its peri-urban area.

Particularly, nine new archaeological sites were identified: S1, S2, S3 and S4 located along the northwestern border of the urban area between 380 and $420 \mathrm{~m}$ a.s.l., S5, S6, S7, S8 and S9 on the slope that limits to the southeast the urban area at elevations between 360 and $380 \mathrm{~m}$ a.s.l.

The archaeological study of these new sites highlights a different frequentation of the area over time. The oldest period of frequentation (VI-I century BC) is attested by site S1 where high rates of black-painted ceramics, terracotta figures, lamps, ointment jars, votive, balsam and a miniaturist pedestal were found: these materials are probably related to the presence of a place of worship. The late Republican period (II-I century BC) is identified in site S2 where the presence of a villae rusticae is hypothesized. Sites S3, S4, S5 and S8 witness to the medieval period, while the chronological constraints of sites S6, S7 and S9 are less clear because of the large time spans revealed by the archaeological materials. Despite the limited number of analysed cadastral units, the acquired data allow to assume that in the peri-urban area there has been a continuity of life until the medieval period.

The application of non-invasive diagnosis techniques allowed for discovering hidden archaeological structures in a predictive way (sites G1-G7) and the location of interesting buildings was determined for each of the seven surveyed area. The most important results were obtained in one of the periurban sites (G4) where the geophysical anomalies that emerged from the survey suggest the presence of a semicircular public building on split levels that is probably a theatre. Direct archaeological excavations will be programmed with the purpose to verify the nature of the identified anomalies.

Acquired topographic, geological and geomorphological data suggest a strong influence of landscape and environmental features of the Isernia area on settlement choices and anthropic interventions on the territory.

The circuit walls around the urban area delimit fairly well the summit surface with respect to the surrounding slopes. Instead, most of the terrace walls were found just outside the circuit walls, where anthropic and colluvial deposits crop out. They were built in order to locally reduce the slope gradients and prevent soil erosion and landslides. The presence of a thick layer of anthropic deposits on the terrace surface and along its borders allow supposing that the archaeological potential of the historical centre of Isernia is mainly concentrated here.

The integrated examination of geological, topographicgeomorphologic and archaeological data also highlights a strong correlation between the environmental setting and the degree of conservation of the archaeological record.

Particularly, archaeological evidences with a good to excellent degree of conservation have been recognized on the surface of the elongated ridge where travertine deposits crop out. Conversely, the lack of the circuit walls in correspondence of some slope concavities located along the border of the surface most likely was caused by ancient landslides. Moreover, reworked archaeological findings recognized in the peri-urban area include some blocks whose actual location within the Carpino valley is probably due first to slope processes and then to riverbank erosion and fluvial transport, and pottery fragments found along the Sordo River valley flanks that were probably transported downslope by gravity and running water. Non-invasive extensive geophysical survey, realized for the first time in the territory of Isernia, has allowed for the location and/or better definition of several new and interesting archaeological structures and address future archaeological explorations.

The use of quantitative integrated data obtained with a multidisciplinary approach of measurements allowed drawing up an updated computerized map of the archaeological heritage of Isernia that represents a product useful for the promotion and enhancement of the territory.

\section{ACKNOWLEDGEMENT}

Special thanks are due to the Superintendency for the Archaeological Heritage of Molise Region for its assistance during fieldwork planning and execution. 


\section{REFERENCES}

[1] C. Peretto, J. Arnaud, J. Moggi-Cecchi, G. Manzi, S. Nomade, A. Pereira, C. Falguères, J.-J. Bahain, D. Grimaud-Hervé, C. Berto, B. Sala, G. Lembo, B. Muttillo, R. Gallotti, U. T. Hohenstein, C. Vaccaro, M. C., M. Arzarello, "A Human Deciduous Tooth and New 40Ar/39Ar Dating Results from the Middle Pleistocene Archaeological Site of Isernia La Pineta, Southern Italy", in: PLOS ONE, October 12, 2015.

[2] Q. Shao, J.-J. Bahain, C. Falguères, C. Peretto, M. Arzarello, A. Minelli, U. T. Hohenstein, J.-M. Dolo, T. Garcia, N. Frank, E. Douville, "New ESR/U-series data for the early Middle Pleistocene site of Isernia la Pineta, Italy", in: Radiation Measurements, 2011, vol. 46, p. 847-852, ISSN: 1350-4487.

[3] V. Castellani, "La struttura sotterranea dell'antico acquedotto di Aesernia (Isernia)", in Journal of Ancient Topography, n. I, 1991, pp. 113-128.

[4] G. Marasco, A.S De Rose, "Il tempio della colonia latina di Isernia, III secolo a. C.", in: Le cattedrali di Isernia e Venafro, il santuario dei SS. Cosma e Damiano. Lions club 2000, pp. 17-39.

[5] C. Terzani, "Isernia Santa Maria delle Monache. Scavi del complesso monumentale", in Conoscenze 1, Campobasso, 1984, pp. 196-198.

[6] C. Terzani, "Isernia, scavi della necropoli romana", in Conoscenze 1, Campobasso, 1984, pp. 224-226.

[7] C. Terzani, M. Matteini Chiari, "La necropoli", in C. Terzani e M. Matteini Chiari (a cura di), Isernia. La necropoli romana in località Quadrella, pp. 31-43.

[8] C. Terzani, "Il complesso monumentale romano di via S. Ippolito", in Tutela, $\mathrm{V}$ settimana Beni culturali, catalogo della mostra, Matrice, 1989, pp. 99-100.

[9] C. Terzani, "Isernia: scavi nel cortile del palazzo vescovile", in Tutela, V settimana Beni culturali, catalogo della mostra, Matrice, 1989, pp. 95-96.

[10] T. Quaranta, "Un supporto per il centro storico. Il parcheggio coperto di Via Occidentale", in Polis idee e cultura nelle città, Isernia e la provincia, Anno III, n. 13, pp. 114-115.

[11] M. Raddi, "Località Fonte Citrone: Relazione delle attività preventive archeologiche nell'area per la realizzazione di un parcheggio". Isernia 22/09/2008.

[12] D. Catalano, N. Paone, C. Terzani, "Isernia", Iannone Editore, Isernia, 2001.

[13] D. Di Bucci, G. Naso, S. Corrado, I. M. Villa, "Growth, interaction and seismogenic potential of coupled active normal faults (Isernia Basin, central-southern Italy)". Terra Nova, 2005, vol. 17 , pp. $44-55$.

[14] M. Coltorti, G. Feraud, A. Marzoli, C. Peretto, T. Ton-That, P. Voinchet, J.J. Bahain, A. Minelli, U. Thun Hohenstein, "New $40 \mathrm{Ar} / 39 \mathrm{Ar}$, stratigraphic and palaeoclimatic data on the Isernia La Pineta Lower Palaeolithic site, Molise, Italy". Quaternary International, 2005, vol. 31, pp. 11-12.

[15] http://www3.regione.molise.it/flex/cm/pages/ServeBLOB.php /L/IT/IDPagina/8634.

[16] M. Cremaschi, "La serie pleistocenica di Isernia La Pineta (Molise) e la posizione stratigrafica dei suoli di abitato paleolitici in essa inclusi”. In: Isernia La Pineta. Un accampamento più antico di 700.000 anni, M. Coltorti (Ed.), Calderini, Bologna, 1983, pp. 49-62.

[17] E. Patacca, P. Scandone, "Geology of the Southern Apennines", in: Italian Journal of Geoscience, 2007, spec. issue n. 7, pp. 75119 .
[18] A. Ascione, A. Capalbo, D. Capolongo, S. Mazzoli, F. Pazzaglia, E. Valente, M. Zattin, "Uplift vs. denudation in the Southern Apennines: geomorphologic evidence and constraints from terrestrial cosmogenic nuclides and apatite $(\mathrm{U}-\mathrm{TH}) / \mathrm{He}$ data, in: Rendiconti Online della Società Geologica Italiana, 2012, vol. 21, pp. 1102-1104.

[19] V. Amato, P.P.C. Aucelli, M. Cesarano, B. Jicha, V. Lebreton, R. Orain, G. Pappone, P. Petrosino, E. Russo-Ermolli, "Quaternary evolution of the largest intermontane basin of the Molise Apennine (central-southern Italy)", in: Rendiconti dei Lincei, 2014, vol. 25, pp. 197-216, doi:10.1007/s12210-0140324-y.

[20] M. Coltorti. M. Cremaschi, M.C. Delitala, D. Esu, M. Fornaseri, A. McPherron., M. Nicoletti, R. Van Otterloo, C. Peretto, P. Sala, V. Schmidt, J. Sevink "Reversed magnetic polarity at Isernia La Pineta, a new lower Paleolithic site in Central Italy". Nature, 1982, vol. 300, pp. 173-176.

[21] D. Esu, "Malacofaune continentali della serie "La Pineta" Isernia”. In: Isernia La Pineta. Un accampamento più antico di 700.000 anni. M. Coltorti (Ed.), Calderini, Bologna, 1983, pp. 539.

[22] F. Cambi, N. Terrenato, "L'impostazione della ricerca" in: Introduzione all'archeologia dei paesaggi", Arti Grafiche Editoriali Srl, Urbino, 2004, pp. 117-159.

[23] P. Mauriello, D. Patella, "A data-adaptive probability-based fast ERT inversion method", Progress In Electromagnetics Research, 2009, vol.97, pp. 275-90.

[24] P. Mauriello, D. Patella, "Resistivity anomaly imaging by probability tomography". Geophysical Prospecting, 1999, vol.47, No.3, pp. 411-429.

[25] F. Cammarano, B. Di Fiore, D., Patella, P. Mauriello "Examples of application of electrical tomographies and radar profiling to Cultural Heritage". Annals of Geophysics, 2000, vol. 43, pp. 309-324.

[26] Alaia, R., D. Patella, P. Mauriello, "Application of the geoelectrical 3D probability tomography in a test-site of the archaeological park of Pompei (Naples, Italy)", Journal of Geophysics and Engineering, 2008, vol. 5, pp. 67-76, doi: 10.1088/1742-2132/5/1/007.

[27] V. Compare, M. Cozzolino, P. Mauriello, D. Patella, "Resistivity probability tomography at the Castle of Zena (Italy)", Journal of Image and Video Processing, Eurasip, 2009, vol. ID 693274, ISSN: 1687-5176, doi: 10.1155/2009/693274.

[28] V. Compare, M. Cozzolino, P. Mauriello, D. Patella, "3D Resistivity probability tomography at the prehistoric site of Grotta Reali (Molise, Italy)", Archaeological Prospection, 2009. vol. 16, n.1; pp. 53-63, ISSN: 1099-0763, doi: 10.1002/arp.347.

[29] M. Cozzolino, E. Di Giovanni, P. Mauriello, A. Vanni Desideri, D. Patella, "Resistivity tomography in the Park of Pratolino at Vaglia (Florence, Italy)", Archaeological Prospection (www.interscience.wiley.com), 2012, Vol. 19, Issue 4, pp. 253260, DOI: 10.1002/arp.1432, 2012.

[30] M. Cozzolino, P. Mauriello, D. Patella, "Resistivity Tomography Imaging of the substratum of the Bedestan Monumental Complex at Nicosia, Cyprus", Archaeometry, 2012, Vol. 56, Issue 2, pp. 331-350, DOI: 10.1111/arp.12018.

[31] L. B. Conyers, D. Goodman, Ground penetrating radar. An introduction for archaeologists, AltaMira Press. Division of Sage Publications, Inc., 1997.

[32] C. Terzani, "Scavo archeologico della cinta muraria di Aesernia", in: Fasti on Line Documents \& Research, 2005. 